\title{
Vulnerabilidades na infância: experiências maternas no cuidado à saúde da criança
}

Vulnerability in childhood: mothers' experiences in caring for their child's health

Vulnerabilidad en la infancia: experiencias maternas en el cuidado de la salud del niño

Débora Falleiros de Mello', Leticia Pancieri², Monika Wernet ${ }^{3}$, Raquel Dully Andrade ${ }^{4}$ Jaqueline Silva Santos ${ }^{5}$, Marta Angélica Iossi Silva ${ }^{6}$

\footnotetext{
${ }^{1}$ Enfermeira, Doutora em Enfermagem. Professora Associada do Departamento de Enfermagem Materno Infantil e Saúde Pública da Escola de Enfermagem de Ribeirão Preto da Universidade de São Paulo (EERP/USP). Ribeirão Preto, São Paulo, Brasil. E-mail: defmello@eerp.usp.br.

2 Enfermeira. Ribeirão Preto, São Paulo, Brasil. E-mail: lepancieri@yahoo.com.br.

${ }^{3}$ Enfermeira, Doutora em Enfermagem. Professora Doutora do Departamento de Enfermagem da Universidade Federal de São Carlos. São Carlos, São Paulo,

Brasil. E-mail: monika.wernet@gmail.com.

${ }^{4}$ Enfermeira, Doutora em Enfermagem. Professora Titular da Fundação de Ensino Superior de Passos. Belo Horizonte, Minas Gerais, Brasil. E-mail: radully@gmail.com.

${ }_{5}^{5}$ Enfermeira. Belo Horizonte, Minas Gerais, Brasil. E-mail: jaque fesp@hotmail.com.

${ }^{6}$ Enfermeira, Doutora em Enfermagem em Saúde Pública. Professora Doutora do Departamento de Enfermagem Materno Infantil e Saúde Pública da EERP/USP. Ribeirão Preto, São Paulo, Brasil. E-mail: maiossi@eerp.usp.br.
}

\section{RESUMO}

O estudo teve como objetivo analisar as vulnerabilidades na infância na perspectiva materna frente ao cuidado à saúde de crianças menores de um ano no contexto da atenção primária à saúde. Estudo exploratório, qualitativo, fundamentado no quadro conceitual da vulnerabilidade. Dezesseis mulheres foram entrevistadas e os resultados apontam aspectos sobre vulnerabilidades sociais, necessidades de saúde e lacunas no apoio e rede social para o cuidado cotidiano de crianças. A escolaridade, renda familiar, trabalho e vaga em creche contribuem para os cuidados de saúde e garantia dos direitos da criança. Em contraponto, a interrupção dos estudos, maternidade na adolescência, pouca oportunidade de emprego, uso de drogas e incipiências na rede de apoio social são apontadas como de vulnerabilidade. A análise das vulnerabilidades na perspectiva materna permitiu refletir limites para o cuidado da criança, com desdobramentos para a integralidade e promoção de saúde neste contexto.

Descritores: Criança; Vulnerabilidade a Desastres; Cuidados de Enfermagem; Enfermagem Pediátrica.

\section{ABSTRACT}

The objective of this study was to analyze the childhood vulnerabilities from the mother's view regarding the care they give to children one year old and younger within the context of primary health care. This exploratory, qualitative study was founded on the conceptual framework of vulnerability. Interviews were performed with sixteen women and the results point at aspects regarding social vulnerability, health needs, and gas in support and social network for the everyday care of children. Education, family income, work, and a place in day care centers contribute to health care and to granting children's rights. On the other hand, quitting school, becoming a teenage mother, having few job opportunities, using drugs and the incipient social support network are pointed out as vulnerability. The analysis of vulnerabilities from the mothers' perspective permitted a reflection about the limits for the care to children, with effects on comprehensiveness and health promotion within this context.

Descriptors: Child; Vulnerabilidad ante Desastres; Nursing Care; Pediatric Nursing.

\section{RESUMEN}

Se objetivó analizar las vulnerabilidades en la infancia, en la perspectiva materna ante el cuidado de la salud de niños de menos de un año, en el contexto de la atención básica de salud. Estudio exploratorio, cualitativo, fundamentado en marco conceptual de la vulnerabilidad. Fueron entrevistadas dieciséis mujeres. Los resultados determinan aspectos sobre vulnerabilidades sociales, necesidades de salud y vacíos en el apoyo y red social para el cuidado cotidiano del niño. La escolaridad, ingreso familiar y vacante en guarderías contribuyen al cuidado de la salud y garantizan los derechos del niño. En contraposición, la interrupción de los estudios, maternidad adolescente, escasa oportunidad de empleo, uso de drogas y carencias en la red de apoyo son determinadas como vulnerabilidades. El análisis de las vulnerabilidades en la perspectiva materna permitió reflejar límites para el cuidado del niño, con implicancias hacia la integralidad y promoción de salud en este contexto.

Descriptores: Niño; Disaster Vulnerability; Atención de Enfermería; Enfermería Pediátrica. 


\section{INTRODUÇÃO}

Práticas integrais na atenção à saúde da criança estão como prioritárias nas políticas públicas brasileiras, sobretudo a partir do estabelecimento da Agenda de Compromisso para a saúde integral da criança e redução da mortalidade infantil de $2004^{(1)}$ e a Política Nacional de Promoção da Saúde (PNPS), de 2006(2). Contudo, ainda há lacunas assistenciais para uma efetiva integralidade na

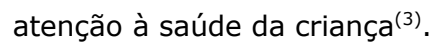

Tais práticas recomendam intervenções nos problemas de saúde, nas condições de vida e nos riscos e danos à saúde, com consideração para a criança como uma pessoa em crescimento e desenvolvimento e integrante de uma família. Nesse sentido, é relevante a análise de inequidades sociais, o contexto sociocultural e familiar, a posição socioeconômica e as diferenças nas vulnerabilidades e nos desfechos de saúde na infância(4), bem como as necessidades e direitos da criança(5).

Considerando a necessidade de se valorizar a família tanto quanto o contexto em que a criança vive ${ }^{(6)}$, na saúde infantil é importante observar vários aspectos, entre eles as condições ambientais (adequação das moradias, moradias precárias e/ou densamente ocupadas e saneamento do meio ambiente); a renda familiar e sua relação com a disponibilidade de alimentos, a qualidade da moradia e o acesso a serviços essenciais; a escolaridade dos membros da família e sua relação com a utilização da renda e dos serviços públicos existentes, as oportunidades de emprego e de salários; acesso e qualidade da assistência dos serviços de saúde, a falta ou a deficiência de assistência pré-natal, a ocorrência de morbimortalidade infantil e a adesão aos serviços de saúde ${ }^{(1,7)}$.

Estudo $^{(4)}$ aponta que crianças de famílias pobres, em comparação com aquelas de famílias mais ricas, são mais suscetíveis à exposição a agentes patogênicos, e uma vez expostas têm um risco aumentado de adoecer, devido à sua menor resistência e menor cobertura de medidas preventivas. Também foi verificado que quando as crianças ficam doentes têm menor acesso aos serviços de saúde, a qualidade dos serviços tende a ser inferior e com menor acesso a tratamentos que garantam sua sobrevivência e, como consequência, as crianças de famílias menos favorecidas apresentam maiores taxas de mortalidade e maior risco de terem problemas nutricionais, exceto a obesidade infantil(4).

Nas últimas três décadas, o Brasil teve avanços nos serviços de saúde e transformações nos determinantes sociais das doenças, constituindo ainda um desafio as condições adversas entre crianças de famílias menos favorecidas, cabendo destacar que é essencial o entendimento da natureza dos problemas e o estabelecimento de intervenções que possam reduzir as diferenças sociais e de saúde ${ }^{(4,7)}$. A morbimortalidade nos primeiros cinco anos de vida da criança tiveram melhorias em seus indicadores, contudo ainda são um dos maiores desafios, sobretudo no primeiro ano de vida da criança ${ }^{(7-}$ 8).

Assim, os profissionais de saúde precisam aliar-se às famílias para um cuidado integral à saúde da criança, fortalecendo-a e proporcionando o apoio necessário à construção de corresponsabilidades ${ }^{(9)}$, porém sem substituí-la. As práticas adotadas pela família no cuidado à criança têm influência direta no processo de crescimento e desenvolvimento saudável ${ }^{(1)}$, bem como as atitudes profissionais $^{(10)}$.

No presente estudo, o foco principal é a visão materna sobre vulnerabilidades na infância, buscando subsídios para o cuidado integral à saúde das crianças e suas famílias, para ampliar os conhecimentos de profissionais e gestores acerca dos aspectos que embasam o cuidado de crianças pelas mães, e contribuir com a definição e implementação de intervenções que garantam maior potencial de crescimento e desenvolvimento infantil. Assim, este estudo teve por objetivo analisar as situações de vulnerabilidade na infância na perspectiva materna, frente ao cuidado à saúde de crianças menores de um ano no contexto da atenção primária à saúde.

\section{MÉTODO}

Trata-se de estudo exploratório, com análise qualitativa dos dados, fundamentado no quadro conceitual da vulnerabilidade ${ }^{(11)}$.

O quadro conceitual da vulnerabilidade no âmbito da área da saúde considera os aspectos individuais, coletivos e contextuais, que podem implicar no aumento de susceptibilidade às doenças e, concomitantemente, um aumento ou diminuição de recursos protetores.

Os componentes da vulnerabilidade individual são, basicamente, de ordem cognitiva (quantidade e qualidade de informação de que os indivíduos dispõem e capacidade de elaborá-la) e de ordem comportamental (capacidade, habilidade e interesse para transformar essas preocupações em atitudes e ações protegidas e protetoras $)^{(11)}$. No âmbito individual, a vulnerabilidade a algum agravo está relacionada aos comportamentos que criam oportunidades para que as pessoas venham a contrair doenças ou situações de dificuldade e sofrimento. Esses comportamentos associados à maior vulnerabilidade não são entendidos e abordados como 
uma decorrência imediata da ação voluntária das pessoas, mas estão relacionados tanto com condições objetivas do ambiente quanto com as condições culturais e sociais em que os comportamentos ocorrem, bem como com o grau de consciência que as pessoas têm sobre tais comportamentos e ao efetivo poder que podem exercer para transformá-los ${ }^{(11)}$.

O componente social da vulnerabilidade envolve o acesso às informações, às possibilidades de entender tais informações e de incorporá-las na vida cotidiana, condições essas diretamente associadas ao acesso a recursos materiais, às instituições sociais como escola e serviços de saúde, ao poder de influenciar decisões políticas, à possibilidade de enfrentar barreiras culturais e de estar livre de coerções violentas de todas as ordens, entre outras, que precisam, então, ser incorporadas às análises de vulnerabilidade e aos projetos educativos as quais elas dão sustentação(11).

O componente programático ou institucional da vulnerabilidade está ligado aos componentes individual e social. Ele congrega o grau e a qualidade de compromisso, recursos, gerência e monitoramento de programas nacionais, regionais ou locais de prevenção e cuidado, aspectos relevantes para identificar as necessidades e os recursos sociais existentes e para otimizar seu uso(11).

$\mathrm{Na}$ presente investigação procurou-se analisar as experiências maternas quanto às situações sociais para o cuidado cotidiano da criança, a partir de uma pesquisa exploratória, com o propósito de explorar aspectos de uma situação e descrever determinado fenômeno(12).

A investigação foi desenvolvida na área de abrangência de uma Unidade de Saúde da Família, em Ribeirão Preto/SP - Brasil, na qual residem famílias provenientes de diferentes regiões brasileiras, que, em geral, mudam para o município em busca de melhores condições de trabalho e de vida.

Essa unidade de saúde está vinculada à rede pública de serviços básicos de saúde do município e atende uma população de cerca de 3.800 pessoas, predominantemente jovem, com famílias vivendo em condições precárias de vida.

A coleta de dados foi baseada em entrevistas semiestruturadas com mães de crianças menores de um ano de idade. Para a coleta dos dados, inicialmente foram realizadas algumas reuniões com os Agentes Comunitários de Saúde da Unidade de Saúde da Família para levantar as famílias das microáreas provenientes de outras regiões brasileiras que não o Estado de São Paulo. No ano de 2010, o número total de famílias com crianças menores de um ano era de 27 , em seguimento na unidade de saúde da família escolhida para realizar este estudo. Das 27 famílias, 11 não participaram, sendo sete em que as mães ou cuidadores não foram localizadas, após três tentativas de visita ao domicílio, e quatro mudaram da área de abrangência da unidade de saúde.

As entrevistas foram realizadas nos domicílios com as mães. Os critérios de inclusão foram: mães/famílias provenientes de diferentes regiões brasileiras, residir na área de abrangência da unidade de saúde da família escolhida, ter crianças menores de um ano de idade, e as crianças estarem em seguimento da saúde infantil na referida unidade de saúde da família. Os critérios de exclusão foram: mães que trabalhavam fora de casa, mães com problemas de saúde mental, crianças sem seguimento na unidade de saúde. Participaram do estudo 16 mães de crianças menores de um ano.

As entrevistas partiram de uma questão norteadora: "Para você quais são as dificuldades para cuidar da saúde do seu filho(a)?".

$\mathrm{Na}$ análise dos dados, foram percorridas as etapas de pré-análise (leitura do material empírico buscando mapear os relatos e significados atribuídos pelos sujeitos); identificação de significados; elaboração de temas (síntese do material empírico) e análise final (discussão dos temas) ${ }^{(13)}$. Para fins analíticos, foram apreendidos aspectos sobre o cuidado da criança e vulnerabilidades na perspectiva materna, ressaltando que esses aspectos não se apresentaram isoladamente, entrelaçando-se e indicando múltiplas dimensões. Nesse processo, os resultados foram agrupados em dois temas: Apoio e rede social para o cuidado cotidiano de crianças, Vulnerabilidades sociais e necessidades de saúde da criança.

A investigação obteve aprovação junto ao Comitê de Ética em Pesquisa do Centro de Saúde Escola da Faculdade de Medicina de Ribeirão Preto-USP, seguindo as normas e recomendações para a pesquisa envolvendo seres humanos. O presente artigo está vinculado a um projeto maior intitulado "Promoção da saúde infantil: a enfermagem construindo espaços de cuidados da criança no contexto da família", que foi aprovado em Comitê de Ética em Pesquisa, sob protocolo no 439/CEP-CSE-FMRPUSP. As mães das famílias selecionadas foram convidadas e esclarecidas quanto aos objetivos e forma de participação, tendo o aceite explícito por meio da assinatura do Termo de Consentimento Livre e Esclarecido.

\section{RESULTADOS}

As mães que participaram do estudo tinham entre 17 e 29 anos de idade e todas eram migrantes dos seguintes 
Estados: Bahia, Goiás, Maranhão, Alagoas, Pernambuco, Pará e Piauí. O tempo que residem em Ribeirão Preto variou de dois meses a 15 anos. O motivo da migração foi a busca por melhores condições econômicas e de trabalho.

As crianças menores de um ano, tendo por base o momento da entrevista, apresentaram os seguintes dados de saúde: oito com aleitamento materno exclusivo até o sexto mês de vida, três com aleitamento misto e cinco introduziram o aleitamento artificial nos seis primeiros meses; 10 estavam com a vacinação completa e seis tiveram atraso vacinal por ocorrência de alguma enfermidade; cinco crianças estavam com alteração no gráfico de crescimento, com peso ou comprimento abaixo do percentil 3 do gráfico de crescimento; quatro crianças foram hospitalizadas, sendo uma por prematuridade, uma para cirurgia de correção de polidactilia nas mãos, uma por bronquiolite e pneumonia, e uma por pneumonia.

A partir da análise das entrevistas maternas foi possível a apreensão de algumas vulnerabilidades no cotidiano do cuidado das crianças, de acordo com os temas construídos, apresentados a seguir.

\section{Lacunas no apoio e rede social para o cuidado cotidiano de crianças}

Neste tema, os aspectos ressaltados estão ligados ao apoio social e à rede social, no que se relaciona à sua constituição e vínculos, os quais muitas vezes se mostram fragilizados. Os participantes relatam as pessoas e as instituições importantes para a família e para a criança, assim como referem algumas diferenças no cuidar com relação às regiões de origem de suas famílias e mencionam elementos importantes dos direitos da criança.

No cuidado da criança, a mãe conta com o apoio de pessoas do entorno familiar, com destaque para avós, cunhada e madrinha da criança. Em relação ao apoio social, as pessoas mencionadas pelas entrevistadas foram a avó materna e paterna da criança, configurando pessoas do entorno familiar.

Às vezes ele começa a chorar demais e eu não sei o que é. Eu não tenho o dom de saber o que é. Você nunca sabe se a criança tá chorando de fome ou se é pra tomar banho, se é pra trocar. Mas, aí vem minha mãe, vem minha cunhada. A minha cunhada também me ajuda. Mas, eu sozinha não dou conta não. (E8)

Só no comecinho, assim nos primeiros dias pra dar mama que eu não conseguia e pra dar banho que eu fiquei com medo. (E14)
É a madrinha que cuida. Ela cuida bem melhor que eu. (E5)

É complicado, a gente não sabe muita coisa. Eu peço mais o apoio da minha mãe pra me ajudar. Comigo o que foi mais difícil foi essa parte de quando ele é novinho, pra dar mamar, tem vez que ele se engasga. Mas, aí minha mãe vem e ajuda. (E7)

Com o pai da T. eu não tenho contato não. É ele lá e eu cá. Ela [criança] tem que ele [pai] vai lá uma vez ou outra. (E1)

As pessoas referidas são figuras femininas que constituem um apoio social, auxiliam no cuidado da criança e na resolução de dificuldades e dúvidas para o desempenho do cuidado, sendo muitas vezes intermediadoras da relação mãe-filho. Também há menção da relação com o pai da criança que, em caso de separação do casal, pode constituir uma situação vulnerável pelo pouco contato com o pai.

As mulheres entrevistadas relatam algumas instituições e setores em sua rede social que são relevantes para o cuidado cotidiano da criança com suporte para seu desenvolvimento.

Ah eu percebi que depois que ela entrou pra creche ela ficou mais espertinha sabe. Parece que desenvolve mais rápido, tá falando mais. (E16)

Na pastoral da criança eles ficam sempre assim, todo mês vem e fazem uma visita em casa, perguntam como que tá a criança, se precisa de alguma coisa, também eles ajudam. Só se você precisar de alguma coisa eles te ajudam, se precisar de algum remédio, se precisar de alguma roupa, sapato também eles dão. (E8)

Aqui é mais o núcleo [unidade de saúde da família] e a igreja mesmo, a gente vai toda semana na igreja. (E15) Se tiver que acontecer uma coisa daqui uma semana o médico já vai saber. Se tiver uma bolinha diferente que vai inflamar o médico já fala. Muita coisa, eu aprendo muito. Cuidar da criança, não deixar ela pegar assadura, não deixar ficar chiado nela[criança]. (E8)

Para as mulheres entrevistadas, na rede social são ressaltados os serviços de saúde, a igreja, a creche e organização não governamental, sendo lembrado o papel da Pastoral da Criança. São locais onde as mães podem contar com ajuda, levar suas dúvidas e dificuldades e obter suporte.

Outras situações de cuidado da criança relatadas nas entrevistas trazem aspectos sobre algumas crenças que 
comparam às práticas de seu local de origem, além de ações, desejos e dificuldades.

Eu já vi o povo da Bahia por no umbigo, tinha que queimar aquelas peninhas e colocar o pozinho. Dos meus filhos eu só curei com álcool e caiu. Eu não tive sisma não. (E13) Eu faço xarope de mel com alho, o lambedor de alho. Sempre do tempo dos avós. Tem vez que eu dou pra ele, pra gripe. Eu faço um lambedozinho com mel, alho e limão, eu ponho uma gotinha, aí dou pra ele e corta mais a tosse, a gripe. (E7)

Olha, nos primeiros dias, como ele chorava muito eu via que forçava o umbigo dele, estufava quando ele chorava, eu colocava faixinha. A minha mãe que ajudou, ela falou pra eu colocar faixinha. Mas, aí eu fui deixando, eu fui desacostumando porque secava muito mais rápido. Aí eu fui tirando e também porque o médico falou que não precisava. (E6)

Eu não quero tirar a mama dele não, mesmo voltando a trabalhar, quero continuar no peito. (E14)

Tudo o que tem que fazer eu vou fazendo, uma hora eu vou acertar. Quando eu vejo que eu não vou acertar mesmo, aí eu dou umas gotinhas de Tylenol e passa. Aí eu sei que é uma dorzinha mesmo. Mas, primeiro eu vou fazendo uma massagem. Quando eu vejo que não tem jeito, aí eu dou o remédio. (E8)

Os relatos acima se referem ao manejo de algumas situações com o uso de objetos, chás ou comidas específicas ligadas à recomendações de pessoas mais velhas de outras gerações e de costumes aprendidos na família ou na comunidade onde moravam. Algumas mães ficam em dúvida se acreditam ou não nos resultados que essas medidas podem trazer para o cuidado da criança.

\section{Vulnerabilidades sociais e necessidades de saúde da criança}

Neste tema, os aspectos ressaltados relacionam as vulnerabilidades sociais às condições socioeconômicas das famílias que vivem na área de abrangência da unidade de saúde analisada, sendo enfatizada a influência em algumas necessidades de saúde da criança.

Os relatos a seguir trazem aspectos dos motivos da vinda dessas pessoas e famílias para outro município.

A minha vida lá era boa, só faltava dinheiro. Aí eu precisava trabalhar, aí vim pra cá e fiquei aqui. (E1)

Minha mãe e meu pai vieram pra cá. Meu pai veio pra trabalhar, aí minha mãe veio logo em seguida e eu fiquei morando com minha vó. Aí depois eles me trouxeram, assim que eles conseguiram se estabilizar. (E3)

A gente veio a trabalho, porque lá trabalho é difícil pra gente. A cidade não tem trabalho pra pessoa trabalhar, aí a gente veio por causa disso. Veio primeiro meu marido, ele veio na frente. Aí com seis meses eu vim. (E11)

Foi porque meu pai tinha que vir pra operar do coração, ele tinha problema no coração. Aí a gente veio pra cá procurando fazer a cirurgia nele, aí a gente veio, ele operou e depois que ele operou ele não quis mais voltar pra lá. Lá os médicos eram muito raros, e quando conseguia atendimento pra médico os médicos são muito ruins. (E16)

Lá é bom, mas o problema é mais a seca. A seca, o sol é difícil pra água, pra trabalho. Aí não tinha as condições, aí nós viemos pra cá. Mas minha família é toda de lá. (E7)

Cabe destacar que o principal motivo da mudança de município foi a busca por trabalho e melhores condições salariais. Alguns consideram que o local onde moravam é bom, mas as condições sociais não favorecem o trabalho e a renda.

Nas entrevistas também foi possível apreender aspectos sobre a escolaridade e a visão materna da influência no cuidado da criança.

Eu quero estudar pra ele ser alguém na vida, porque se eu não estudar como é que ele vai aprender? Tem muitas coisas que, se ele cair doente. Pelo menos saber ler é bom. (E2)

O fato de você estudar, eu acho que na criação já vai ser totalmente diferente, que você tem um estudo a mais, você tem um conhecimento a mais. Então, é lógico que ela [criança] vai aprender um pouquinho mais do que eu. Porque eu já vou passar algumas coisas que eu já estudei, e ela vai aprender muito mais. Porque, no caso, a minha mãe estudou só o ensino fundamental, ela nunca me passou nada. Ela não tinha estudo nenhum, não sabia nada. Então, tudo o que eu tinha que aprender foi sozinha. (E3)

Parece que a gente por estudar parece que pega mais informação. E quando não estuda não tem informação nenhuma. Então, cuida bem, mas não cuida tão bem como quem estuda. (E5)

Eu acho que ajuda, porque eu entendo as coisas. Mais para dar os remédios pra ele. Nos cuidados não precisar ficar perguntando pros outros as coisas, eu mesma sei. (E9) 
Sempre é bom a gente saber ler, pra aprender medicar o bebê. Porque tudo eu dependo do meu marido, ele tem que deixar tudo certinho pra mim. (E13)

Os relatos maternos expressam o que elas pensam sobre o estudo, saber ler e escrever e como a educação escolar como um fator que influencia positivamente no desenvolvimento e crescimento da criança, que o próprio estudo facilita o cuidar dos filhos.

Alguns relatos expressam dificuldades vivenciadas e enfrentamento de vulnerabilidades.

Eu to feliz com o meu bebê. Todos os problemas que eu passei, porque eu passei problema, passei luta. Meu marido entrou nas drogas, ele me largava abandonada e eu ficava sozinha na minha gravidez. Só que depois também ele parou, ele enxergou mais, ele dá mais carinho pros meninos [filhos], que isso ele não dava. Agora ele quietou dentro de casa. Ele vivia com os amigos dele lá fora que não é a família dele. Ele tá enxergando aos poucos as coisas. (E13)

Eu era muito magra. E eu dava o leite, eu dava. Eu não tinha leite. Até os dois meses foi tudo bem. Mas, ele chorava muito, bastante. Eu dava o leite e ele não se satisfazia com o leite do peito só. É que era difícil de amamentar. (E2)

As situações relatadas pelas mulheres trazem os aspectos que elas visualizam sobre o contexto social e que têm interface com os componentes individuais, e ressaltam que tais condições interferem na saúde da criança.

Outros aspectos mencionados pelas entrevistadas dizem respeito aos direitos da criança.

Ele tem direitos. Eu só preciso sair daquele fundo lá, sair daquela casa. Eu quero a minha casa e que não tenha barro. Aquele barro da minha casa me mata. (E1)

Ter educação e acho que uma boa alimentação também. Acho que é direito deles. Casa limpa e roupa limpa. Acho que higiene, segurança e alimentação são os principais. (E6)

Tem o direito de brincar, de se divertir, isso. (E11)

As entrevistadas relatam importantes elementos dos direitos da criança e expressam preocupação com situações vulneráveis do cotidiano. Há um olhar para o contexto social em que vivem, e como conseguem perceber lacunas e prover um cuidado aos filhos.

\section{DISCUSSÃO}

A apreensão do modo como as famílias se organizam e dos vários fatores sociais e individuais coexistentes tem grande relevância para a saúde, que devem ser considerados desde o nascimento da criança até sua inserção nos programas públicos de atenção à saúde infantil. Para o planejamento do cuidado em saúde é vital conhecer os aspectos vinculados ao apoio social e à rede social que a família busca no cotidiano e em sua historicidade.

A utilização dos instrumentos genograma e ecomapa mostram o desenvolvimento e formato da estrutura da família, fornecem informações sobre o contexto de vida da família. Durante a sua construção a família é envolvida ativamente, relatando a história de sua origem, as particularidades dos seus membros, os acontecimentos significativos de suas histórias e as condições de saúde da família(14). Neste estudo, ocorreu uma aproximação entre os sujeitos (entrevistado/entrevistador) por meio da utilização desses instrumentos, conduzindo ao estabelecimento de confiança para conversar sobre a composição da família e as experiências de cuidar da criança durante o primeiro ano de vida, oportunizando aos familiares uma reflexão sobre o apoio que eles têm tanto dentro quanto fora da própria família, na vivência de ter o filho e cuidar dele e na busca de novas formas de enfrentar as situações vivenciadas pela família.

Rede social e apoio social são conceitos interrelacionados, mas com algumas diversificações entre si, sendo que a "rede social refere-se à dimensão estrutural ou institucional, ligada a um indivíduo [...]. O apoio social encontra-se na dimensão pessoal, sendo constituído por membros desta rede social efetivamente importante para as famílias"(15). Na rede social fazem parte as instituições relacionadas à família, tais como as organizações religiosas, o sistema de saúde, a escola e a vizinhança e, como parte do apoio social, os membros dessa rede social que são significativos para as famílias e seus membros ${ }^{(16)}$. $\mathrm{O}$ apoio e a rede social auxiliam no fortalecimento da família frente às suas experiências de vida, atuando na redução da taxa de mortalidade, na prevenção de agravos à saúde e também na recuperação da saúde ${ }^{(16)}$.

Para famílias com dificuldade de acesso a recursos de saúde e educação e com acentuada limitação de recursos econômicos, as creches comunitárias proporcionam um suporte considerável, amenizando algumas dificuldades relacionadas à alimentação e contribuindo para a educação e promoção de hábitos de vida saudáveis ${ }^{(17)}$.

A participação da família no cuidado é muito importante, porque representa o ambiente primário e 
principal referência na infância, sendo a interação entre pais e filhos a base para a criança construir sua identidade e adaptar-se aos eventos da vida. Pela dependência da criança, cabe à família um papel estruturador, no suprimento de suas necessidades básicas como alimentação, calor, abrigo e proteção e também para proporcionar um ambiente no qual possa desenvolver ao máximo as suas capacidades físicas, mentais e sociais ${ }^{(18)}$.

O vínculo entre pais e filho é fundamental para o desenvolvimento da criança e a enfermagem pode desempenhar um papel importante, mediando as relações e criando espaços de cuidado para a proteção e promoção da saúde da criança e família.

Após o nascimento do bebê, torna-se imprescindível cuidar para que as atenções não estejam voltadas apenas para ele, deixando à mãe o mero papel de objeto do aleitamento e dos cuidados; é preciso ampliar as ações e o olhar profissional, tendo em vista as experiências maternas e familiares, bem como seus projetos de vida ${ }^{(19)}$. Na grande maioria das famílias, é a mãe quem assume o papel de cuidar e, portanto, o interesse das mães no cuidado da criança e o modo como percebe o crescimento e desenvolvimento da criança define como ela prestará cuidado a seu filho ${ }^{(18)}$.

As mães entrevistadas citaram crenças e tradições que rotineiramente seguem no cuidado à criança. Neste sentido, é importante ressaltar que cada família tem sua própria cultura além daquela da comunidade onde ela vive, principalmente quando se trata de famílias que migraram de outra região como é o caso das famílias abordadas. A interação com o seu contexto social de origem, refletindo acerca de práticas culturalmente aprendidas, são trazidas ou não para o cuidado do filho.

Estudo observou que as mães reconhecem a Unidade de Saúde da Família como referência para a saúde de seus filhos $^{(6)}$, onde apreendem o conhecimento ofertado nas práticas pelos profissionais de saúde. Entretanto, quando elas se encontram no contexto domiciliar e social em que vivem, o conhecimento e o discurso familiar e comunitário exercem certa hegemonia sobre o que foi conduzido pelos profissionais $^{(20)}$. De algum modo, as mães podem se ver em uma situação contraditória, entre discursos opostos, na qual prevalecerá as informações mais presentes e com maior força em seu cotidiano.

Nesse sentido, a omissão de um profissional da saúde no cotidiano de cuidado domiciliar da criança irá desencorajar as mães a seguirem em frente com os cuidados que vivenciaram na instituição de saúde, deixando evidente a importância do enfermeiro se imergir no contexto social, de forma a conhecer e envolver as pessoas do entorno familiar no processo de ensinoaprendizagem do cuidado da criança, estimulando uma fusão de conhecimentos ${ }^{(9)}$ em prol da promoção da saúde da criança.

Sendo assim, é fundamental que o enfermeiro busque conhecer o significado cultural e social das práticas, evitando atitudes de julgamento depreciativo de hábitos diferentes, facilitando a comunicação e promovendo a confiança(17)

Para contemplar resultados relevantes na saúde da criança são necessárias a identificação e compreensão dos valores, crenças, atitudes, decisões e projetos das mães e famílias. Portanto, os profissionais de saúde precisam utilizar de suas habilidades de comunicação e observação para conhecer o contexto sociocultural das mães e famílias e identificar suas práticas de cuidado para que possam dar crédito às suas crenças, visando sempre conciliar o respeito à dimensão cultural do cuidado materno com o conhecimento científico sobre as necessidades da criança $^{(17)}$. Fortalecer o vínculo do profissional com o usuário dos serviços de saúde colabora para que aumente sua confiança, e a construção de relacionamentos confiantes e seguros ocorre de forma gradual(21).

As mulheres entrevistadas consideram que o nível de escolaridade, a renda familiar, o trabalho e a criança estar na creche, podem trazer benefícios aos cuidados de saúde da criança, assim como relatam e percebem os direitos da criança. Há um reconhecimento delas sobre as situações de vulnerabilidades sociais quanto à interrupção dos estudos, pouca oportunidade de emprego e o uso de drogas do cônjuge. Os aspectos sociais visualizados pelas mães/mulheres têm interface com os componentes da vulnerabilidade individual, de ordem cognitiva, comportamental e afetiva. A vulnerabilidade individual do ponto de vista de aspectos cognitivos é importante ser analisada porque está relacionada à elaboração de informações recebidas, e do ponto de vista comportamental e afetivo tem relação com as capacidades, habilidades e interesses para transformar as preocupações em atitudes e ações protetoras ${ }^{(11)}$.

Se os profissionais da atenção primária em saúde não conhecem as famílias e suas condições de vida e de saúde, eles ficam distantes delas e isso constitui um tipo de vulnerabilidade programática, ou seja, o serviço de saúde pode tornar-se vulnerável porque não oferece uma atenção à saúde de acordo com as reais necessidades das famílias e crianças. O profissional de saúde, ao levantar as necessidades de saúde, identificar as vulnerabilidades, procurar solucionar problemas e dúvidas, intervir adequadamente e compreender sofrimentos, entre outros 
aspectos, pode evitar o aumento das vulnerabilidades individuais e sociais, contribuindo para a construção do cuidado integral em saúde.

\section{CONSIDERAÇÕES FINAIS}

A análise das vulnerabilidades na infância sob a ótica materna permitiu identificar que no componente da vulnerabilidade individual, as mães fazem uso de saberes aprendidos em sua história de vida com seu entorno social. Estas se confrontam com as práticas ensinadas no sistema de saúde, especialmente junto aos profissionais das unidades da rede básica de serviços públicos de saúde.

Quanto ao componente social da vulnerabilidade, o estudo mostra que as mulheres/mães reconhecem a escolaridade como aspecto que interfere na compreensão e uso de informações para o cuidado da criança. O acesso à creche e aos serviços de saúde são recursos de contribuição para o crescimento e desenvolvimento da mesma. Ressalta-se ainda o fato de todas as integrantes do estudo terem migrado de seus estados em busca de melhorias nas suas condições financeiras. Em relação ao componente programático da vulnerabilidade, as mulheres utilizam-se, sobretudo dos seguintes recursos sociais: creche, serviço de saúde, igreja e organizações não governamentais. Contudo, não se percebeu em seus relatos serem agentes que exercem controle social com

\section{REFERÊNCIAS}

1. Ministério da Saúde. Secretaria de Atenção à Saúde. Departamento de Ações Programáticas Estratégicas. Agenda de compromisso para a saúde integral da criança e redução da mortalidade infantil. Brasília: Ministério da Saúde; 2004. 2. Ministério da Saúde. Política Nacional de Promoção da Saúde. Brasília: Ministério da Saúde; 2006.

3. Cursino EG, Fujimori E. Integralidade como uma dimensão das práticas de atenção à saúde da criança: uma revisão bibliográfica. Ver Enferm UERJ. 2012; 20(esp1):676-80. 4. Barros FC, Victora CG, Scherpbier R, Gwatkin D.

Socioeconomic inequities in the health and nutrition of children in low/middle income countries. Rev. Saúde Pública 2010; 44(1):116.

5. Andrade RD, Mello DF, Silva MAI, Ventura CAA. Advocacia em saúde na atenção à criança: revisão da literatura. Revista Brasileira de Enfermagem. 2011;64(4):738-44.

6. Furtado MCC, Braz JC, Pina JC, Mello DF, RAG. A avaliação da atenção à saúde de crianças com menos de um ano de idade na Atenção Primária. Rev. Latino-Am. Enfermagem.

2013;21(2):554-61

7. Victora CG, Aquino EML, Leal MC; Monteiro CA, Barros FC, Szwarwald CL. Saúde de mães e crianças no Brasil: progressos e desafios. The Lancet 2011;377(9780):1863-1876.

8. Walker SP, Wachs TD, Grantham-McGregor S, Black MM, Nelson CA, Huffman SL, et al. Inequality in early childhood: risk and protective factors for early child development. Lancet. 2011;378(9799):1325-38.

9. Mello DF, Lima RAG. Technical attainment, practical success and practical knowledge: hermeneutical bases for child nursing care. Rev Latino-Am Enferm. 2009; 17(4):580-585. vistas às melhorias na saúde das crianças, família e comunidade.

As mães apontam o que elas conhecem e com o que se preocupam na saúde da criança, e apreender os diferentes aspectos sobre isso é fundamental aos profissionais de saúde para averiguar o que precisa ser incentivado, elogiado, trabalhado, modificado e compreendido, para a expansão dos cuidados nos domicílios, bem como em conjunto com outros setores sociais. Quanto à rede social, destacou-se o vínculo com o profissional de saúde, especialmente o de nível local. Portanto, cabe aos profissionais de saúde conhecer e compreender a estrutura e a dinâmica familiar para identificar as reais necessidades, reconhecer barreiras e contribuir para um cuidado à saúde de todos seus membros, em busca, ainda, de um incremento de responsabilidades na promoção da saúde, prevenção de agravos, tratamento e recuperação da saúde, de forma integral e ao longo do tempo.

Este estudo trouxe aspectos que visam atribuir mais sentido às práticas de atenção à saúde da criança, sendo importante ressaltar que outras pesquisas podem ser exploradas para avançar em questões ligadas às singularidades familiares e comunitárias, em busca de compreensão da amplitude do processo saúde-doença, das vulnerabilidades e do cuidado em saúde.

10. Erdmann AL, Sousa FGM. Cuidando da criança na Atenção Básica de Saúde: atitudes dos profissionais da saúde. O Mundo da Saúde. 2009; 33(2):150-160.

11. Ayres JRCM et al. O conceito de vulnerabilidade e as práticas de saúde: novas perspectivas e desafios. In: Czeresnia D, Freitas $C M$, orgs. Promoção da saúde: conceitos, reflexões, tendências. Rio de Janeiro (RJ): Fiocruz; 2003. p. 117-39.

12. Marconi MA, Lakatos EM. Fundamentos da metodologia científica. 6a Ed. São Paulo: Atlas; 2007.

13. Gomes R. Análise de dados em pesquisa qualitativa. In: Minayo MCS (organizadora). Pesquisa social: teoria, método e criatividade. 23a. ed. Petrópolis, RJ: Vozes; 2004. p.67-80. 14. Wright LM, Leahey M. Enfermeiras e famílias: um guia para avaliação e intervenção na família. $4^{a}$.ed. São Paulo: Roca; 2008. 294.

15. Pedro ICS, Rocha SMM, Nascimento LC. Apoio e rede social em enfermagem familiar: revendo conceitos. Rev Latino-am Enfermagem 2008; 16(2): 324-27.

16. Bullock K. Family social support. In: Bomar PJ. Promoting health in families: applying family research and theory to nursing practice. 3 ed. North Carolina: Saunders, Elsevier; 2004. 17. Remor CB, Pedro VL, Ojeda BS, Gerhardt LM. Percepções e conhecimentos das mães sobre higiene. Esc Anna Nery RevEnferm. 2009; 13(4): 786-92.

18. Britto PR, Ulkuer N. Child development in developing countries: child rights and policy implications. ChildDevelopment. 2012; 83(1):92-103. 19. Souza SNDH, Mello DF, Ayres JRCM. O aleitamento materno na perspectiva da vulnerabilidade programática e do cuidado. Cad. Saúde Pública. 2013; 29(6):1186-1194.

20. Cabral IE, Groleau D. Breastfeeding practices after kangaroo mother method in Rio de Janeiro: the necessity for health 
education and nursing intervention at home. Esc Anna Nery Rev Enferm 2009;13(4):763-71

21. Mello DF, Furtado MCC, Fonseca LMM, Pina JC. Seguimento

da saúde da criança e a longitudinalidade do cuidado. Rev. Bras.

Enferm. 2012; 65(4):675-9.

Artigo recebido em 21/11/12.

Aprovado para publicação em 11/11/13.

Artigo publicado em 31/03/2014. 